Revta brasil. Bot., São Paulo, V.24, n.1, p.73-77, mar. 2001

\title{
Morfogênese in vitro e susceptibilidade de calos de variedades nacionais de cana-de-açúcar (Saccharum officinarum L.) a agentes seletivos utilizados em sistemas de transformação genética
}

\author{
MARCELO AGUIAR COSTA LIMA ${ }^{1}$, RENATA DE OLIVEIRA GARCIA ${ }^{1}$, GILBERTO \\ SACHETTO MARTINS ${ }^{2}$ e ELISABETH MANSUR ${ }^{1,3}$
}

(recebido: 29 de março de 2000; aceito: 28 de outubro de 2000)

\begin{abstract}
In vitro morphogenesis of Brazilian sugarcane (Saccharum officinarum L.) varieties and callus susceptibility to selective markers used in genetic transformation systems). In vitro morphogenesis from immature leaf explants excised from field-grown plants of two Brazilian sugarcane (Saccharum officinarum L.) cultivars (RB739735 and RB72454) was evaluated. Explants were obtained from 6-9 month-old plants and cultured on solid MS medium supplemented with $9 \mu \mathrm{M} 2,4$-dichlorophenoxyacetic acid (2,4-D). Cultures were maintained in the dark for four weeks. The efficiency of callus formation was influenced by the genotype. Calli derived from cv. RB72454 were mucilagenous and did not originate plants. Explants from cv. RB739735 formed yellow, friable embryogenic (type II) calli, which kept their proliferative capacity for at least six months. Upon transfer to hormone-free medium and light conditions, 56\% of these calli regenerated plants, resulting in an average recovery of 50 plants per callus, after two months of culture. Plants developed further and originated lateral shoots in liquid MS0 medium. No phenotypic abnormalities were observed. Growth inhibition of calli in response to different concentrations of antibiotics used in genetic transformation protocols was also evaluated. Inhibition was observed in the presence of $128.7 \mu \mathrm{M}$ kanamycin and $94.8 \mu \mathrm{M}$ hygromycin. No inhibitory effect of geneticin (G418) was obtained at concentrations between 43.3 and $86.6 \mu \mathrm{M}$.
\end{abstract}

RESUMO - (Morfogênese in vitro e susceptibilidade de calos de variedades nacionais de cana-de-açúcar (Saccharum officinarum L.) a agentes seletivos utilizados em sistemas de transformação genética). Foi avaliada a morfogênese in vitro a partir de explantes de folha imatura excisados de plantas de duas variedades nacionais (RB739735 e RB72454) de cana-de-açúcar (Saccharum officinarum L.), mantidas em campo. Os explantes foram obtidos de plantas com 6-9 meses e cultivados em meio MS sólido suplementado com 2,4-D a $9 \mu \mathrm{M}$. As culturas foram mantidas no escuro, durante quatro semanas. A eficiência de formação de calos foi influenciada pelo genótipo. Os calos derivados da variedade RB72454 eram mucilaginosos e não originaram plantas. Explantes da variedade RB739735 formaram calos amarelos friáveis e embriogênicos (tipo II), que mantiveram sua capacidade proliferativa por, pelo menos, seis meses. Após transferência para meio MS sem reguladores de crescimento e em condições de iluminação, $56 \%$ desses calos originaram plantas, resultando na produção de, em média, 50 plantas por calo, após dois meses de cultura. As plantas continuaram a se desenvolver, originando novos brotos após transferência para meio MS0 líquido, não sendo observadas anormalidades fenotípicas. A inibição do desenvolvimento dos calos em resposta a diferentes concentrações de antibióticos usados em protocolos de transformação genética foi também avaliada. Foi observada inibição na presença de canamicina a $128,7 \mu \mathrm{M}$ e de higromicina a $94,8 \mu \mathrm{M}$. Não foi obtido nenhum efeito inibidor do antibiótico geneticina (G418), em concentrações entre 43,3 e 86,6 $\mu \mathrm{M}$.

Key words - Sugarcane, antibiotics, in vitro morphogenesis

\section{Introdução}

A cana-de-açúcar é uma gramínea perene pertencente ao gênero Saccharum, da tribo Andropogoneae, família Poaceae (Gramineae). É uma cultura que produz, em curto período, um alto rendimento

1. Universidade do Estado do Rio de Janeiro, Instituto de Biologia Roberto Alcântara Gomes, Departamento de Biologia Celular e Genética, Rua São Francisco Xavier 524, Maracanã, Pavilhão Haroldo Lisboa da Cunha, sala 218, 20550-013 Rio de Janeiro, RJ, Brasil.

2. Universidade Federal do Rio de Janeiro, Instituto de Biologia, Departamento de Genética, Cidade Universitária, Centro de Ciências da Saúde, bloco A, sala A2-066.

3. Autor para correspondência: mansur@uerj.br de matéria verde, energia e fibras, sendo considerada uma das plantas com maior eficiência fotossintética. Seu plantio em larga escala é tradicional em vários países das regiões tropical e subtropical para a produção de açúcar, álcool e outros subprodutos. Entretanto, a presença de plantas com características desfavoráveis nas plantações pode reduzir drasticamente o rendimento da cultura (Enriquez-Obregón et al. 1998).

O cultivo in vitro já foi descrito para diversas variedades, através da cultura de calos e meristemas, com obtenção de altas taxas de multiplicação (Hendre et al. 1986, 1993). Srinivasan \& Vasil (1986) e Chen et al. (1988) descreveram a regeneração de plantas a partir de protoplastos, embora seus resul- 
tados não tenham sido reproduzidos por outros pesquisadores (Liu 1994). A indução de calos embriogênicos já foi obtida em explantes de cana-de-açúcar inoculados em meio suplementado com diversos tipos de auxina (Ho \& Vasil 1983, Fitch \& Moore 1990, Brisibe et al. 1994). Taylor et al. (1992) descreveram a indução de calos organogênicos e embriogênicos em 18 cultivares, bem como a obtenção de culturas de células em suspensão. A regeneração de plantas a partir de calos embriogênicos obtidos através do cultivo de explantes de inflorescência imatura foi observada por Blanco et al. (1997) em meio suplementado por 2,4-D (ácido 2,4 diclorofenoxiacético) e por Liu (1993), utilizando diferentes combinações de 2,4-D, cinetina, 6-BA (6-benzilaminopurina) e pantetonato de cálcio. Arencibia et al. (1995, 1997, 1998) e Enríquez-Obrigón et al. (1998) desenvolveram protocolos de transformação genética por eletroporação de tecidos intactos ou através da Agrobacterium tumefaciens, adaptando com sucesso o sistema embriogênico descrito por Ho \& Vasil (1983) a variedades cubanas, e obtiveram plantas transgênicas com expressão de genes marcadores e resistência a herbicidas.

A transformação genética de cana-de-açúcar foi descrita por Chen et al. (1987), que obtiveram massas celulares transgênicas a partir de protoplastos tratados com polietilenoglicol (PEG) sem, contudo, alcançar a regeneração de plântulas. A expressão transiente de genes exógenos em protoplastos e a expressão estável em calos foram descritas por Rathus \& Birch (1992), utilizando eletroporação. Plantas transgênicas foram obtidas através da utilização de métodos diretos e indiretos de transformação, incluindo a eletroporação de tecidos meristemáticos (Arencibia et al. 1992) e fragmentos de calo (Arencibia et al. 1995), o bombardeamento de calos embriogênicos (Bower \& Birch 1992, Gallo-Meagher \& Irvine 1996) e outras técnicas baseadas na utilização da Agrobacterium tumefaciens (Arencibia et al. 1997, 1998, EnríquezObrigón et al. 1998).

Este trabalho é parte de um projeto que tem como objetivo o estabelecimento de protocolos de transformação genética, visando à obtenção de variedades nacionais com baixo teor de lignina, que possam ser utilizadas como matéria-prima para a produção de papel e alimentação animal. Até o mo- mento, poucos protocolos de regeneração in vitro encontram-se disponíveis para variedades nacionais. Neste trabalho foi desenvolvido um protocolo de indução de calos e regeneração para as variedades RB739735 e RB 72454, cultivadas no estado do Rio de Janeiro. Além disso, foram determinadas as concentrações efetivas de antibióticos utilizados freqüentemente como agentes seletivos em protocolos de transformação genética.

\section{Material e métodos}

Plantas de cana-de-açúcar das variedades RB738795 e RB72545, com 6-9 meses de cultivo em campo experimental, foram gentilmente cedidas pela PESAGRO (Campos/RJ). Folhas imaturas foram desinfestadas por $1 \mathrm{~min}$ em etanol comercial $\left(93,8^{\circ} \mathrm{GL}\right)$ e, em seguida, em solução de hipoclorito de sódio a $2 \%$, por $5 \mathrm{~min}$. Após três lavagens com água destilada estéril, as folhas mais externas foram removidas até a obtenção de um cilindro de aproximadamente $2 \times 10 \mathrm{~cm}$. Segmentos transversais de $1 \mathrm{~cm}$ de comprimento foram excisados e utilizados como explantes. Os explantes foram incubados em meio basal MS (Murashige \& Skoog 1962) geleificado com 0,7\% ágar (SIGMA) e acrescido de sacarose a 3\% e 2,4-D a $9 \mu \mathrm{M}$. O pH do meio foi ajustado a $5,8 \mathrm{com} \mathrm{NaOH}$ a $1 \mathrm{~N}$, antes da adição do ágar e esterilização em autoclave a $120^{\circ} \mathrm{C}$, por 15 min. Aproximadamente $15 \mathrm{~mL}$ de meio foram distribuídos em placas de Petri de $9 \mathrm{~cm}$ de diâmetro. Doze explantes foram distribuídos em cada placa e mantidos no escuro em câmara climatizada à temperatura de $28 \pm 3{ }^{\circ} \mathrm{C}$, tendo sido avaliada a resposta morfogenética de 200 explantes da variedade RB739735 e 80 explantes da variedade RB72454, por um período de 6 meses. Os calos formados foram transferidos para meio de mesma composição após 3-4 semanas e incubados no escuro. Para manutenção, os calos foram divididos em 4-5 fragmentos e incubados nas mesmas condições. Para indução do desenvolvimento de plantas, os calos foram incubados em meio sem adição de reguladores de crescimento e mantidos sob iluminação, com fotoperíodo de $16 \mathrm{~h}$, provido por lâmpadas branca-fria e Grow-Lux (3:1) e intensidade luminosa de $36 \mu \mathrm{mol} \cdot \mathrm{m}^{-2} \cdot \mathrm{s}^{-1}$. Após 4 semanas, as plantas regeneradas com tamanho superior a $2 \mathrm{~cm}$ foram transferidas para meio basal MS líquido, para crescimento e enraizamento, sendo mantidas nas mesmas condições de iluminação. Após o enraizamento, as plantas foram transferidas para meio MS0 geleificado com ágar a $0,7 \%$. A eficiência de indução de calos e regeneração foi determinada com base na percentagem de explantes que formaram calos e no número de plantas recuperadas em cada calo.

Para determinação do efeito inibidor de antibióticos utilizados em protocolos de transformação genética, calos do tipo amarelo friável (tipo II) da variedade RB739735 foram inoculados no meio descrito para regeneração acrescido de diferentes concentrações de monosulfato de canamicina $(42,9 ; 85,8 ; 128,7$ e 171,6 $\mu \mathrm{M})$, higromicina $\mathrm{B}(19 ; 47,4 ; 94,8$ e $142,2 \mu \mathrm{M})$ ou dissulfato de geneticina-G418 (43,3; 57,7; 72,1 e 86,6 $\mu \mathrm{M})$. Os calos submetidos a estes tratamentos foram incubados em câmara de crescimento, na presença de luz. Vinte explantes foram utilizados 
para cada tratamento e os experimentos foram repetidos pelo menos duas vezes.

\section{Resultados e Discussão}

Os explantes de folha imatura das variedades RB739735 e RB72454 originaram calos com freqüências de 70 e $100 \%$, respectivamente, quando cultivados em meio MS suplementado com 2,4-D a $9 \mu \mathrm{M}$. Os explantes da variedade RB739735 deram origem a diferentes tipos de calo: amarelos compactos, amarelos friáveis e brancos friáveis, de forma semelhante à previamente descrita por Arencibia et al. (1995) para outras variedades. Os calos amarelos friáveis, classificados como tipo II (Ho \& Vasil 1983), quando incubados em meio sem reguladores de crescimento e mantidos em presença de luz, originaram plantas completas a partir de 4 semanas, com uma freqüência de $56 \%$. Após a primeira subcultura, a partir de cada calo foram isoladas, em média, 50 plantas. Após o enraizamento e transferência para meio MS sólido, as plantas alongaram e originaram perfilhos (figura 1). Os fragmentos de calo mantiveram sua capacidade proliferativa e características morfológicas por um período de seis meses de observação. Os explantes da variedade RB72454, apesar de apresentarem uma frequiência de indução de calos superior à observada na cultivar RB739735, formaram preferencialmente calos amarelos mucilaginosos, que não originaram plantas (tabela 1). Por-
Tabela 1. Avaliação da resposta morfogenética de segmentos de folha imatura de Saccharum officinarum L. (variedades RB739735 e RB72454) cultivadas em meio MS suplementado por 2,4-D a $9 \mu \mathrm{M}$.

\begin{tabular}{lccc}
\hline Variedade & $\begin{array}{c}\text { Indução de } \\
\text { calos* }\end{array}$ & Regeneração* & $\begin{array}{c}\mathrm{N}^{\circ} \text { médio de } \\
\text { plantas/calo** }\end{array}$ \\
\hline RB739735 & $140 / 200(70 \%)$ & $44 / 80(56 \%)$ & $50 \pm 8$ \\
RB72454 & $80 / 80(100 \%)$ & $0 / 60(0 \%)$ & 0 \\
\hline
\end{tabular}

*explantes responsivos/total de explantes.

**dados após a primeira subcultura.

tanto, a eficiência do processo de indução de calo e diferenciação de broto foi significativamente influenciada pelo genótipo, como ocorre com diversas outras espécies. A regeneração de plantas fenotipicamente normais a partir de calos tipo II, também obtidos na presença de 2,4-D a $9 \mu \mathrm{M}$, já foi observada anteriormente para a variedade brasileira SP701143, com uma recuperação de 3-8 plantas em cada calo (Costa Lima, dados não publicados). Neste trabalho, taxas significativamente mais elevadas foram obtidas, tornando este sistema de regeneração compatível com o desenvolvimento de protocolos de transformação genética para a variedade RB739735.

Como estratégia para avaliar o efeito inibidor dos antibióticos escolhidos, calos amarelos friáveis da variedade RB739735 foram incubados nas condições apropriadas para regeneração de plantas. Desta forma, a resposta dos tecidos foi avaliada em uma

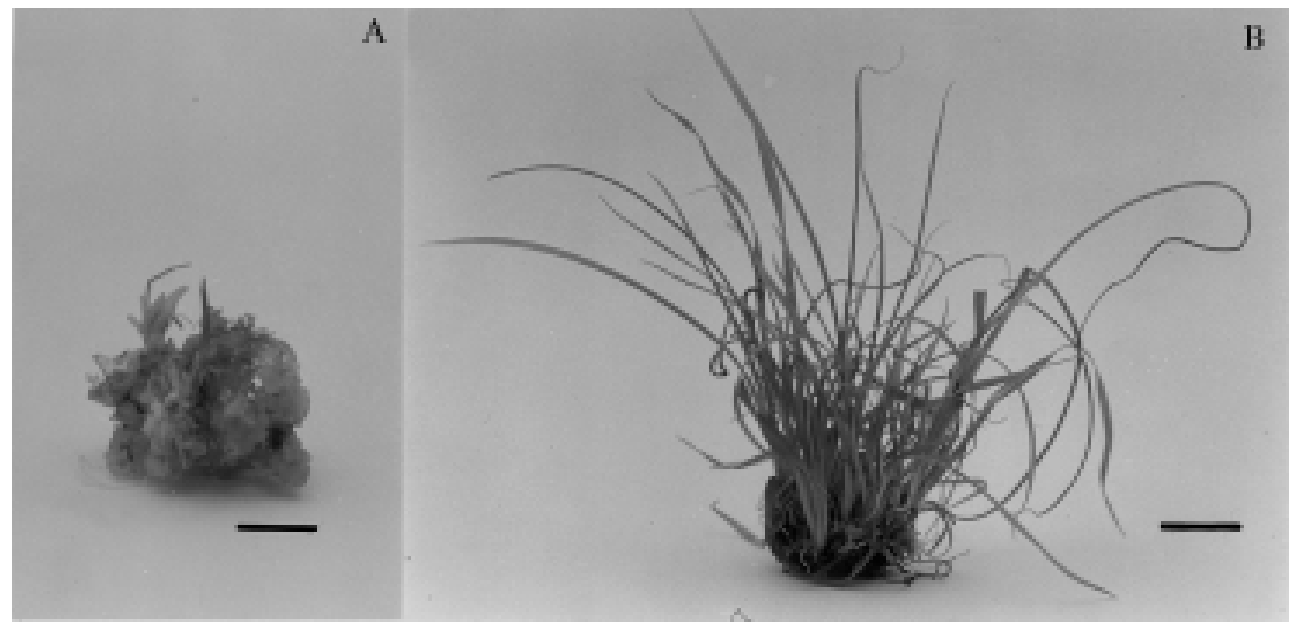

Figura 1. Regeneração in vitro de Saccharum officinarum L. a partir de folhas imaturas da variedade RB739735. Os calos foram induzidos em meio MS suplementado com 2,4 D a $9 \mu \mathrm{M}$, no escuro, transferidos para MS0 geleificado e incubados em presença de luz durante 3 (A) e 8 semanas (B). Barra $=1 \mathrm{~cm}$ 
situação fisiológica equivalente àquela em que se encontrarão durante o procedimento utilizado na transformação genética através da Agrobacterium, permitindo o estabelecimento do padrão de resposta ao marcador seletivo. A necrose dos calos e a inibição da regeneração de plantas foram observadas em presença de sulfato de canamicina a $128,7 \mu \mathrm{M}$. Concentrações mais elevadas provocaram a necrose completa dos tecidos, em um intervalo de tempo não superior a 4 semanas. Nas concentrações inferiores, entretanto, o potencial regenerativo diminuiu, com o desenvolvimento de um número reduzido de plantas com aspecto clorótico. Estes resultados diferem dos descritos por Arencibia et al. (1995), que observaram desenvolvimento de calos em concentrações superiores a 171,6 $\mu \mathrm{M}$ de canamicina. A resposta dos explantes a higromicina apresentou um perfil semelhante ao obtido em resposta a canamicina, sendo a inibição do desenvolvimento de calos e da regeneração de brotos observada em concentrações a partir de 98,4 $\mu \mathrm{M}$. Esta concentração é recomendada como a mais efetiva para seleção em outras espécies (Park et al. 1998). Não houve inibição no desenvolvimento dos calos e na recuperação de plantas em resposta ao antibiótico G418, na faixa de concentrações testada. Com base nestes resultados, foram estabelecidas as primeiras etapas para o desenvolvimento de protocolos de transformação de variedades nacionais de cana-de-açúcar, utilizando Agrobacterium tumefaciens.

Agradecimentos - Os autores agradecem a inestimável colaboração do Dr. Saul Ribas (PESAGRO, Campos/RJ), pelo fornecimento do material de campo e constante disponibilidade. Este trabalho teve apoio financeiro da Comunidade Européia. R.O. Garcia é bolsista de Aperfeiçoamento do CNPq.

\section{Referências bibliográficas}

ARENCIBIA, A., CARMONA E., TELLEZ, P., CHAN, M-T., YU, S., TRUJILLO, L.E. \& ORAMAS, P. 1998. An efficient protocol for sugarcane (Saccharum spp. L.) transformation mediated by Agrobacterium tumefaciens. Transgenic Research 7:213-222.

ARENCIBIA, A., MOLINA, P., DE LA RIVA, G. \& SELMAN-HOUSSEIN, G. 1995. Production of transgenic sugarcane (Saccharum officinarum L.) plants by intact cell electroporation. Plant Cell Reports 14:305-309.
ARENCIBIA, A., MOLINA, P., GUTIERREZ, C., FUENTES, A., GREENIDGE, V., MENENDEZ, E., DE LA RIVA, G. \& SELMAN-HOUSSEIN, G. 1992. Regeneration of transgenic sugarcane (Saccharum officinarum L.) plants from intact meristematic tissue transformed by electroporation. Biotecnologia Aplicada 9:156-165.

ARENCIBIA, A., VÁZQUEZ, R., PRIETO, D., TÉLLEZ, P., CARMONA, E., COEGOI, A., HERNANDEZ, L., DE LA RIVA, G. \& SELMAN-HOUSSEIN, G. 1997. Transgenic sugarcane plants resistant to stem-borer attack. Molecular Breeding 3:247-255.

BLANCO, M.A., NIEVES, N., SÁNCHEZ, M., BORROTO, C.G., CASTILLO, R., GONZÁLEZ, J.L., ESCALONA, M., BÁEZ, E. \& HERNANDÉZ, Z. 1997. Protein changes associated with plant regeneration in embryogenic calli of sugarcane (Saccharum sp.). Plant Cell Tissue and Organ Culture 51:153-158.

BOWER, R. \& BIRCH, R.G. 1992. Transgenic sugarcane plants via microprojectile bombardment. Plant Journal 2:409-416.

BRISIBE, E.A., MIYAKE, H., TANIGUCHI, T. \& MAEDA, E. 1994. Regulation of somatic embryogenesis in long-terms callus cultures of sugarcane (Saccharum officinarum L.). New Phytologist 126:301-307.

CHEN, W.H., DAVEY, M.R., POWER, J.B. \& COCKING, E.C. 1988. Sugarcane protoplasts: factors affecting division and plant regeneration. Plant Cell Reports 7:344-347.

CHEN, W.H., GARTLAND, K.M.A., DAVEY, M.R., SOTAK, R., GARTLAND, J.S., MULLIGAN, B.J., POWER, J.B. \& COCKING, E.C. 1987. Transformation of sugarcane protoplasts by direct uptake of a selectable chimeric gene. Plant Cell Reports 6:297-301.

ENRIQUEZ-OBREGÓN, G.A., VÁZQUEZ-PADRÓN, R.I., PRIETO-SAMSONOV, D.L., DE LA RIVA, G.A. \& SELMAN-HOUSSEIN, G. 1998. Herbicide-resistant sugarcane (Saccharum officinarum L.) plants by Agrobacterium-mediated transformation. Planta 206:20-27.

FITCH, M.M.M. \& MOORE, P.H. 1990. Comparison of 2,4-D and picloram for selection of long-term totipotent green callus of sugarcane. Plant Cell Tissue and Organ Culture 20:157-163.

GALLO-MEAGHER, M. \& IRVINE, J.M. 1996. Herbicide resistant transgenic sugarcane plants containing the bar gene. Crop Science 36:1367-1374.

HENDRE, R.R., GUPTA, V.S., MASCARENHAS, A.F. \& RANJEKAR, P.K. 1986. Differences in repeated DNA sequences between callus and shoot tissue of sugarcane (Saccharum officinarum L.). Indian Journal of Biochemistry \& Biophysics 23:80-86.

HENDRE, R.R., IYER, R.S., KOTWALM, M., KLUSPS, S.S. \& MASCARENHAS, A.F. 1993. Rapid multiplication of sugarcane by tissue culture. SugarCane 1:05-08.

HO, J. \& VASIL, I.K. 1983. Somatic embryogenesis in sugarcane (Saccharum officinarum). The morphology and physiology of callus formation and the ontogeny somatic embryos. Protoplasma 118:169-180.

LIU, M.C. 1993. Factors affecting induction, somatic embryogenesis and plant regeneration of callus from cultured immature inflorescence of sugarcane. Journal of Plant Physiology 141:714-720. 
LIU, M.C. 1994. A novel method of plant regeneration from suspension culture protoplasts of sugarcane. Journal of Plant Physiology 143:753-755.

MURASHIGE, T. \& SKOOG, F. 1962. A revised medium for rapid growth and bioassay with tobacco tissue culture. Physiologia Plantarum 15:473-479.

PARK, S.H., ROSE, S.C., ZAPATA, C., SRIVATANAKUL, M. \& SMITH R.H. 1998. Cross-protection and selectable marker genes in plant transformation. In Vitro Cellular \& Developmental Biology 34:117-121.
RATHUS, C. \& BIRCH, R.G. 1992. Stable transformation of callus from electroporated sugarcane protoplasts. Plant Science 82:81-89.

SRINIVASAN, C. \& VASIL, I. 1986. Plant regeneration from protoplasts of sugarcane (Saccharum officinarum L.). Plant Physiology 126:41-48.

TAYLOR, P.W.J., KO, H.L., ADKINS, S.W., RATHUS, C. \& BIRCH. R.G. 1992. Establisment of embryogenic callus and high protoplast yielding suspension cultures of sugarcane (Saccharum spp. Hybrids). Plant Cell Tissue and Organ Culture 28:69-78. 